\title{
Some challenges to manufacturing engineer education process at TU - Varna
}

\author{
Pavlina Toteva-Lyutova ${ }^{1, *}$, Krasimira Koleva $^{l}$, and Nadezhda Tsoneva $^{1}$ \\ ${ }^{1}$ Technical University of Varna, 1 Studentska Str., Varna, Bulgaria
}

\begin{abstract}
Today's economic development is dynamic, closely connected with high technology applications, a growth in intellectual capital and widespread innovations. Most economically developed countries realise the need to create new solutions to present or upcoming problems. Creating a modern innovative, educational, scientific and technological infrastructure becomes an important issue. The 21 st century sets new challenges to future engineering specialists. The paper analyses the currently demanded engineering competencies and modern requirements to engineer training in order to prepare reliable specialists for the labour market. The purpose of this paper is to present a brief analysis of the syllabi and the content of the separate disciplines which ensure qualified student education. An attempt to include geometrical dimensioning and tolerance in design education at TU Varna was reported in this paper, standards which are the core of geometrical product specifications inevitably required in the age of globalization of industry. The paper gives some hints how to teach efficiently the new generation of GPS standards at the mechanical engineering faculty.
\end{abstract}

\section{Introduction}

The task of modern dynamic relationships between industrial firms and technical universities is not only to prepare students for a particular profession, but also to create a wider choice of application of their knowledge and skills. Upon joining an organization (where "a certain product" is produced) the young engineer should be able to work in the sphere of his speciality not only "de jure" but also "de facto". That can only be achieved if there are a number of conditions and positive outcomes obtained during the period of training and if the graduate has acquired certain knowledge, skills and competencies. One of the necessary conditions is the acquisition of such knowledge in their training, which is applicable to the industry. Students' training depends on many factors such as curricula, qualified lecturers, available material facilities, and learners motivation.

\section{Requirements to engineering education}

Mechanical engineers - designers, technologists, metrologists etc. are an important part of the machine building companies teams as they are in the basis of new products

* Corresponding author: pavlina toteva@abv.bg 
development. Their work is extremely creative - they develop a product concept based on the requirements of the client or the functional managers, as well as their own experience and imagination, supported by the knowledge and skills they have acquired. They personally control the development of the concept into production specifications and their implementation, and also participate in the testing of the product (parts, devices, etc.). The engineer's activities are highly responsible and require continual improving aimed at meeting the requirements of modern technology and economical development.

However, many observations and studies recently, [1], have shown the need of the contemporary industry for employees possessing the so-called STEM (Science, Technology, Engineering \& Mathematics) education and skills. These needs are due to the characteristics of modern industrial development and, in particular, machine-building. Its features include great dynamics, global competition, striving for rapid innovation, flexibility, high energy efficiency [2,3] and low cost and guaranteed quality.

In view of the above-mentioned facts, on the one hand, a variety of traditional and modern possibilities for professional realization of machine engineers is provided, but on the other hand high and variable requirements for their preparation are set.

Fig. 2 shows the activities performed by engineers in modern digital design, manufacturing and operation of products.

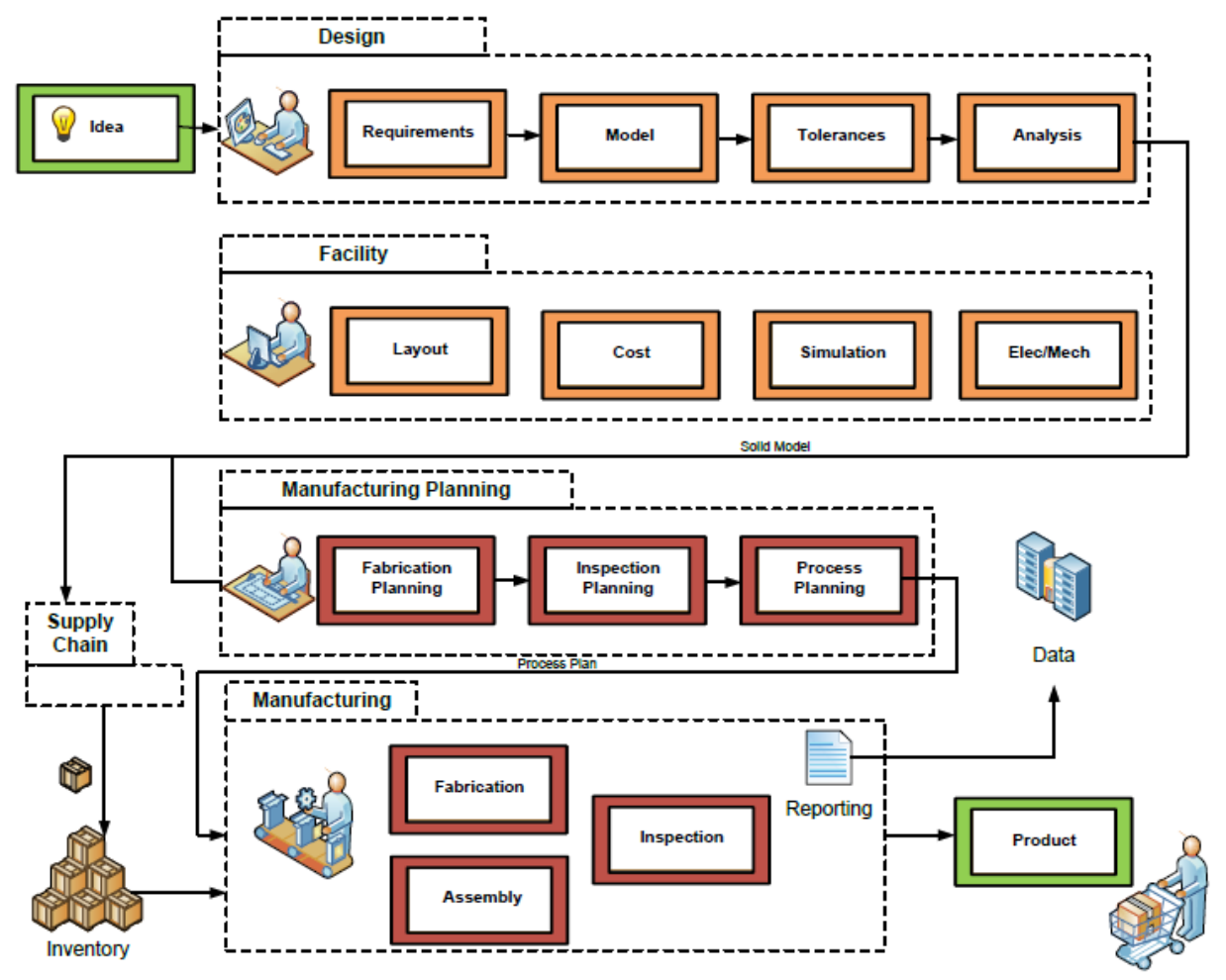

Fig.1. Manufacturing Activities in Product Lifecycle, [4]

Employers and researchers report a sequence of deficits of graduates in mechanical and manufacturing engineering [5]:

$>$ Necessary knowledge of design, manufacturing technologies development as well as metrological training;

$>$ Skills for operation of manufacturing equipment;

$>$ Digital skills; 
Foreign language skills;

Information literacy and decision making skills;

Planning and organizational skills;

$>$ Project management skills;

$>$ Presentation and negotiation skills;

$>$ Problem solving skills;

$>$ Teamwork skills.

The reasons are the low students' motivation for studying in these specialties, the reduced number of academic hours in the separate disciplines and the insufficient number of curricula.

Necessary engineer's knowledge in modern mechanical industry is shown in Fig.2.

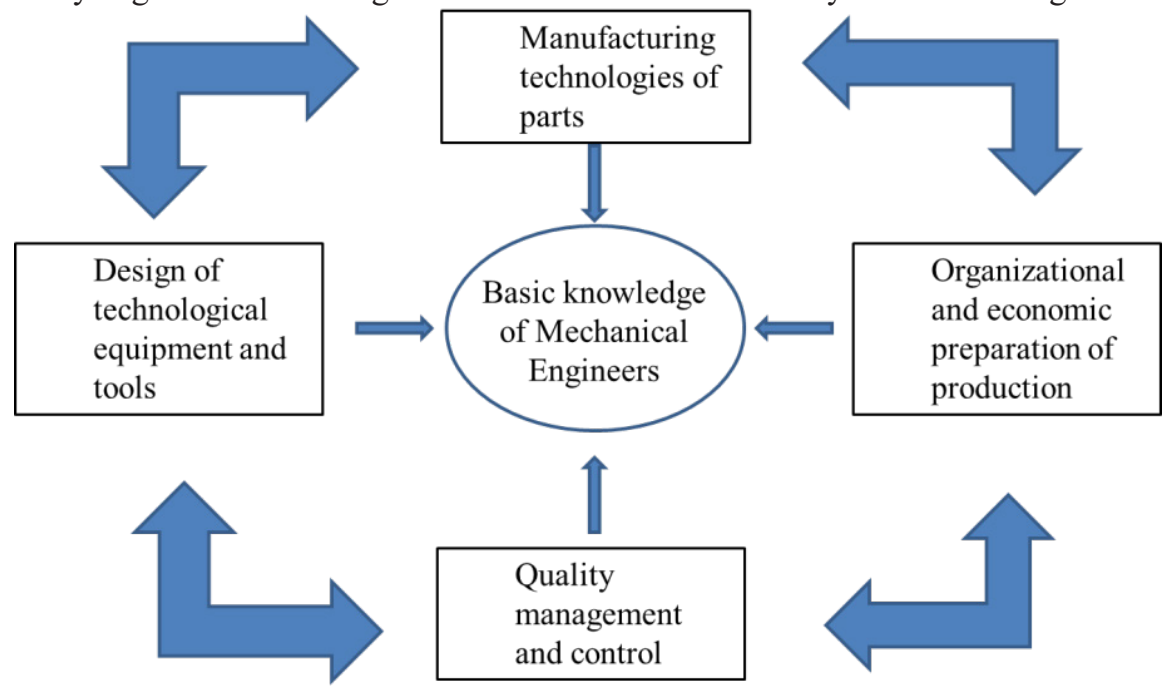

Fig.2. Essential knowledge for the engineer in modern mechanical industry

As seen in Fig. 2, fundamental training is of particular importance for the acquisition of professional knowledge and skills, and it creates the necessary links between the various fields of engineering training. Meanwhile, a number of observations and studies, [1], have recently shown that many companies expect to choose job candidates who are STEM literate graduates. Therefore, there are certain requirements set out in the planning and organization of the teaching-learning process at universities. On the other hand, a continuous reduction in the workload has been observed in recent years which presupposes constant curricula changes and it eventually results in a disruption of the learning process logic.

\section{Position and role analysis of the discipline of Interchangeability and Technical Measurements in the currently applicable curricula for MANUFACTURING ENGINEERS preparation at TU - Varna.}

TU-Varna offers two Bachelor's Degree programs for the preparation of manufacturing engineers: Manufacturing Engineering and Technologies and Computer Aided Manufacturing Technologies (CAMT). Studying CAMT enables students to gain[6]:

Advanced knowledge in: Manufacturing technologies, Manufacturing automation, Product design and optimization by using contemporary CAD/CAE systems, 
$\mathrm{CAD} / \mathrm{CAM}$ technologies for programing machine tools and equipment. Design of manufacturing systems and layout of mechanical workshops. Fundamentals of Computer integrated manufacturing (CIM).

$>$ Acquiring skills to prepare and defend individual engineering projects as well as teamwork.

$>$ Approaches to solve different engineering problems related to design, control and management of production processes. Using contemporary multimedia equipment and software and developing presentation skills and ability to defense projects. Participating in practical trainings and specialized practice in real work environment.

Graduated bachelors in "Computer Aided Manufacturing Technologies" can work as specialists - mechanical engineers in all areas of manufacturing industries and enterprises, or may continue their higher education in Master's Degree courses in the field of Technical Science.

As an example of analyzing the precision of the curricula currently applied, the authors focus on position of the discipline of Interchangeability and Technical Measurements. For that purpose an excerpt of the curriculum of the CAMT speciality is presented in Table 1. The logical connections have been marked between the content of the disciplines related in accordance with the requirements for engineering competencies, [7].

The following conclusions can be drawn from the table presented above:

$>$ As far as the curricula devising is concerned - it is clear that some supported courses were allowed to precede the supporting courses

$>$ As far as the syllabi content is concerned:

The discipline of Interchangeability and Technical Measurements is one of the most important fundamental disciplines applied to all specialized disciplines. It is of utmost importance for the manufacturing engineers to acquire the appropriate knowledge and skills needed to develop design and technological documentation. It is supposed to meet certain requirements:

$\checkmark \quad$ Fulfillment of intended service - each part should be designed and tolerances set in view of its intended service and lifecycle

$\checkmark \quad$ Ensure proper parts assembly

$\checkmark$ Technology - the parts should be manufactured within the tolerance limits, implementing appropriate manufacturing processes, machine tools, cutting tool and operation modes.

A major requirement for the technical documentation is parts to be depicted on drawings in a complete and unambiguous manner. The development of manufacturing digitalization has brought to a cutting edge standardization of accuracy requirements for geometric elements aiming at:

$\checkmark$ Clarification of terminology in order confusion to be avoided when reading the drawings;

$\checkmark$ Consistency in interpreting certain requirements.

In order to overcome these differences, a series of GPS standards, developed by ISO TS 1313, have been introduced into production in recent years.

GPS is a system for product specification based on the principles and practices of dimensioning and tolerancing on a geometrical (and mathematical) basis. It is also a real solution to real industry needs. The GPS-system provides tools necessary in order to express functional requirements more precisely and with more complete and well-defined specification of workpieces. GPS aims at improving communication between: designers, manufacturers and metrologists - by means of a common language with common understanding. 
These new requirements should be adequately incorporated into engineering students training. In the existing curricula the topics concerning the accuracy tolerancing of geometrical characteristics have been included in several disciplines:

There are three topics on parts accuracy included in the syllabus of Engineering Graphics and Technical Drawing:

$>$ Size Accuracy. Tolerances. Main Deviations - 2 academic hours;

$>$ Shape deviation and surfaces and axes orientation and location - 2 academic hours;

$>$ Surface roughness -2 academic hours.

As a matter of fact, these are the requirements for linear dimensions accuracy, introduced in ISO 286-1, the requirements for geometric deviations specified in ISO 1101 and the requirements for surfaces roughness given in ISO 4768-1, respectively.

The Interchangeability and Technical Measurements course comprising 30 academic hours of lectures and 30 academic hours of seminars focuses on topics concerning accuracy requirements for linear sizes, accuracy tolerancing and measuring of threads connections, angles and cone connections, as well as keyways and spline connections.

It is obvious that within these academic hours it is not possible to study in detail the GPS standards and their application.

The aim of Education and training in GPS standards is to give a solid overview of the structure and the main contents of the system.

The main approach in the preparation of constructors, technologists and metrologists is to conduct seminars and courses on implementing into practice the new generation of GPS standards. The curriculum concerning GPS should include: Thirteen ISO fundamental principles, Geometrical characteristics, General tolerances, Linear sizes, Tolerances of form, Datums, Tolerances of orientation, Tolerances of location, Size and ISO system of limits and fits, Angular sizes, Tolerances of any line/surface, Tolerances of run-out, Roughness, waviness and primary profile (2D and 3D), Measurement uncertainty, Complex geometrical features (threads, splines, gears, angles, cones), Material and other modifiers (e.g. E, M, L, R, P, F), Tolerancing of assemblies, dimensional chains, Measurements with the use of conventional measuring devices (callipers, micrometers, dial gauges, bore gauges etc.). Measurements with the use of measuring machines (microscopes, projectors, CMMs), Measurements of form deviations, Measurements of surface roughness (2D and 3D), Measurements in micro- and nanoscale, Inspection by gauges and decision rules for proving conformance or nonconformance with specifications, Calibration of measuring equipment.

These topics are included in a large number of standards, many terms and definitions, a huge number of symbols, operators and modifiers, making it impossible to get detailed learning. To solve this problem it is necessary to develop new training material and to design new training programs to train even the educators. The initial reaction from the industrial users of ISO GPS standards indicates that the education and training material may have to be split into modules that vary in complexity from the simplest to the more advanced.

Simple modules are intended to beginners and relatively simple applications need only a subset of the symbols. But the users need to know about the potential ambiguities that may arise from the use of such simple symbol sets, and their consequences. The users should also be made aware of the default rules that apply if some of the symbols are omitted. It is quite possible that many users are willing to assume the risk, and opt for the simpler set of symbols.

Advanced users will require more training in the use of the new symbols. The major challenge facing them is 'making the business case' for justifying the additional cost of education and training. This requires the development of carefully chosen case studies that show the superior benefits (and the avoidance of costly mistakes) that result from the use of 
the more advanced features of ISO GPS standards. More efforts should be spent in making such a business case.

In addition there are questions related to Implementation of GPS in CAD systems, in CMS and other inspection systems and in data exchange standards.

A conclusion is drawn that either the number of academic hours for the discipline "Interchangeability and Technical Measurements" should be increased or the discipline should be divided into two separate courses - „Interchangeability” and „Technical Measurements". Furthermore, it is of utmost importance to take into account and note all the changes in the standards used in the curriculum content of all disciplines.

Table 1. Excerpts of the curriculum of the speciality of Computer Aided Manufacturing Technologies, Bachelor's Degree.

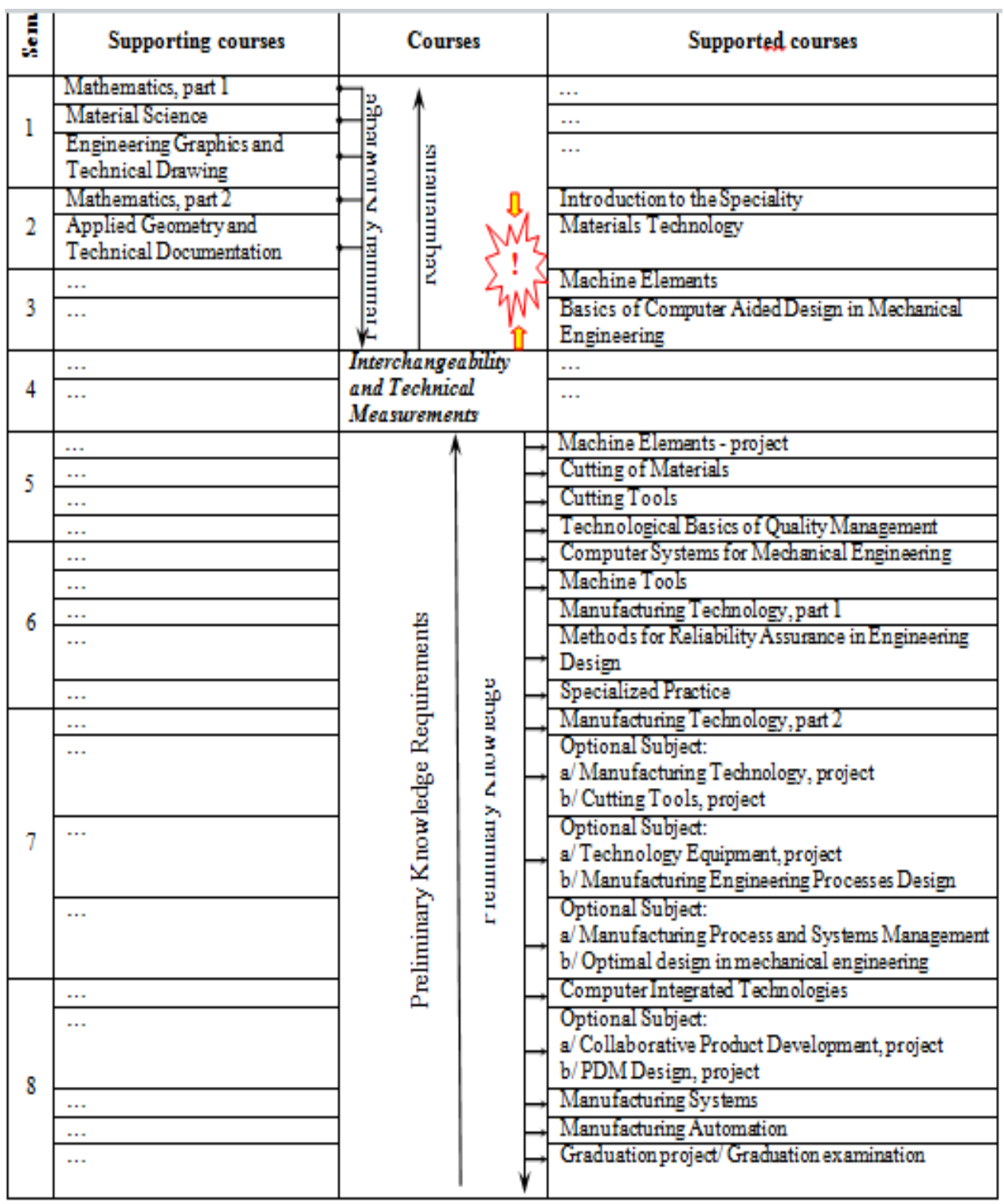


It should be noted that manuals for the practical application of these standards are readily available. Examples of such manuals are the books of G. Henzold, [8,9], Prof. Dr. Ing. W. Jorden, W. Schütte, [10], Bialas, S., Osanna, P.H., Tamre, M.,Weckenmann, A., Blunt, L., Jakubiec, W., et al, [11], the compilation BC 8888, [12].

Unfortunately, these standards have not been translated into Bulgarian yet, they have been introduced in the official languages for ISO - English, German and French. As a consequence this results in ambiguity in the terminology in Bulgarian language.

\section{Conclusions}

A set of measures has been taken at TU - Varna aiming at increasing the popularity and the attractiveness of the mechanical engineer profession:

$>$ Organising a number of informative meetings and different competitions at technical vocational high schools;

$>$ Fostering engineering students high assessment and evaluation;

$>$ Encouraging the process of learning through work experience;

$>$ Providing opportunities for participating in students exchange under the ERASMUS + program.

It is the authors' strong belief that along with these activities there is a need of comprehensive review of the syllabi and developing new ones which will allow for meeting the requirements of future business environment.

\section{Suggestions:}

$>$ The initial point in devising the curriculum should be the end of the training process, using as a background information the employers'requirements. It would be preferable business representatives to take part in the teams developing curricula;

$>$ When devising the curricula, the interrelationships among the syllabi should be noted and the learners should impose requirements on the facilitators. The implementation of tables as Table 1 would enhance the quality of educational documentation;

$>$ Flexibility and opportunity for quick adjustment in case of a change in the requirements of the labour market. This results in the need to include appropriate interchangeable disciplines;

$>$ The content of the syllabi must be determined in a comprehensive and consistent way in compliance with the business requirements;

$>$ Changes to the content of any syllabus are made along with all syllabi concerned.

Finally, the realization of STEM curricula requirements becomes an issue of utmost importance, [13]:

$>$ the context must be relevant and motivating thus students develop personal connections to the learning;

$>$ students must be engaged in the design process, that helps them develop students' creativity and higher-order thinking skills ( 21 st century skills);

$>$ students should have opportunities to learn from failure and redesign, the main objectives of the lesson must include meaningful and important mathematics and/or science content;

$>$ the lessons must incorporate and emphasize teamwork and communication. 


\section{References}

1. BUSINESSEUROPE, "PLUGGING THE SKILLS GAP THE CLOCK IS TICKING", www.businesseurope.eu/sites/buseur/files/media/imported/2011-00855-E.pdf, (2011)

2. И. Колев и др. Изследване коефициента на полезно действие на системата на главния превод на стругове с ЦПУ. Научни трудове на РУ «А. Кънчев», Т.50, С. 4, Русе, ISBN 1311-3321, (2011)

3. И. Колев и др. Изследване влиянието на производителността на рязане върху специфичната консумирана енергия при струговане. Научни трудове на РУ «А. Кънчев», Т.51, C. 2, Pусе, pp.144-152, ISBN 1311-3321, (2012)

4. J. Michaloski T. Hedberg Hui Huang Thomas Kramer, , National Institute of Standards and Technology, , (2016)

5. Данев Б., Състояние и проблеми на оценяването на компетенциите на работната сила, Българска стопанска камара - съюз на българския бизнес, София, (2011).

6. tmmm.tu-varna.bg/index.php/en/training

7. Н. Авдеев, Взгляд неравнодушного профессора на проблемы высшей школь, М.: МГИУ, (2006).

8. Henzold G., Geometrical Dimensioning and Tolerancing for Design Manufacturing and Inspection, Butterworth-Heinemann, (2006)

9. DIN Normenheft 7: Anwendung der Normen über Form-und Lagetoleranzen inder Praxis, Georg Henzold Beuth Verlag, Berlin 20XX, X. Auflage, Georg Henzold, Form und Lage, X. Auflage, Beuth Verlag Berlin 20XX

10. Prof. Dr. Ing. W. Jorden, W. Schütte: Form-und Lagetoleranzen, Hanser Verlag Handbuch für Studium und Praxis ISBN (Buch): 978-3-446-43080-8

11. Bialas, S., Osanna, P.H., Tamre, M.,Weckenmann, A., Blunt, L., Jakubiec, W., et al, in Humienny Z, (Ed.) Geometrical Product Specifications-Course for Technical Universities. Warsaw University of Technology Printing House, Poland, (2001)

12. K. Kiszka, Some Elements of Modern ISO Approach to GPS in UE Training Project for the Specification and Verification of Product Geometry, Machine Dynamics Research Vol. 40, No 4, 89-101, (2016)

13. K. Margot, T. Kettler, Teachers' perception of STEM integration and education: a systematic literature review, International Journal of STEM Education, Vol. 6, (2019) 